\title{
TRABALHO DOCENTE E FORMAÇÃO DE PROFESSORES DO ENSINO MÉDIO: UMA ANÁLISE DAS PRODUÇÕES DA REVISTA BRASILEIRA DE EDUCAÇÃO (RBE)
}

\author{
Néryla Vayne Alves Dias, Patrícia Regina de Souza, Paulo Roberto Brancatti, Renata Portela Rinaldi \\ Universidade Estadual Paulista Júlio Mesquita Filho - UNOESTE, Departamento de Educação e Programa de Pós- \\ Graduação em Educação.
}

\section{RESUMO}

Este artigo versa sobre uma pesquisa teórica na Revista Brasileira de Educação, utilizando como procedimento de coleta de dados o levantamento bibliográfico no período de 2000 a 2016 . Vincula-se a uma pesquisa mais ampla sobre a formação de professores e o trabalho docente nos diferentes níveis de ensino. Nosso foco voltou-se à seleção de textos que tratavam da temática no nível médio. Objetivamos compreender o que revelam as produções, a partir de fatores como: número de publicações, autores, universidades, temas abordados, referenciais utilizados, destacando a relevância, divergências e recorrências do tema. De 459 trabalhos consultados, selecionamos 6. Os resultados evidenciaram que o ensino médio como temática principal, apresenta-se praticamente inexistente nas produções no periódico, entretanto, pesquisas de cunho teórico, com rigor e representatividade, de autores renomados, a partir de referenciais internacionais tratam a temática da formação e o trabalho docente na educação básica, e compreendem também as discussões deste nível.

Palavras-Chave: Trabalho Docente, Formação de Professores, Ensino Médio, Revista Brasileira de Educação, Pesquisa Qualitativa.

\section{ABSTRACT}

This article focuses on a theoretical research in the Brazilian Journal of Education, using as a data collection procedure the bibliographic survey from 2000 to 2016. Our focus was on the selection of texts that deal with teacher training and teaching work in the middle level. We aim to understand what the productions reveal, based on factors such as: number of publications, authors, universities, topics addressed, references used, highlighting the relevance, divergences and recurrences of the theme. Of 459 papers consulted, we selected 6 that approached the theme. The results showed that secondary education as a main subject is practically non-existent from the studies addressed in the journal; however, theoretical research, with rigor and representativeness, by renowned authors, based on international references, deals with the theme of formation and Work in basic education, and also understand the discussions at this level.

Keywords: Bibliographic Survey, High School, Teaching, Teacher Training; Brazilian Journal of Education; Qualitative research. 


\section{INTRODUÇÃO}

A complexidade que envolve a profissão do professor exige uma formação multidimensional, abordando fatores que estão ligados desde aos saberes disciplinares dos conteúdos, saberes da didática e da ação pedagógica, como aspectos mais amplos, relacionados às reais condições de trabalho e das lutas que se travam na busca de reconhecimento da atividade docente como uma profissão respeitada e necessária para a sociedade, que esteja amparada pelas políticas públicas.

Autores como Lapo e Bueno (2003) apontam que a vivência das situações com as quais os docentes se deparam e as problemáticas advindas de uma multiplicidade de fatores como: intensificação do trabalho docente, precarização, desvalorização, condições de trabalho inadequadas etc., acabam por repercutir no mal-estar docente. Sendo esse o fator principal para que os professores abandonem o magistério. Podendo esse abandono ocorrer de modo temporário e chegar a abandonos definitivos.

Fazemos aí um paralelo à formação do professor. Esta deve trabalhar na minimização do choque com a realidade. Em muitos casos, é na formação inicial o primeiro momento em que o aluno se coloca na situação de professor, mesmo que em posição de estagiário. Este momento deve ser problematizado, contextualizado, não abrindo brechas para a construção de crenças de formação de super-professores (JESUS, 2002), pois isso pode refletir negativamente quando o profissional adentrar no campo de trabalho e não se sentir preparado, o que pode ocasionar o malestar ou o abandono precoce da profissão.

Para Develay (2004) o mal-estar docente está ligado, muitas vezes, às causas não confessadas que derivam de uma profissão confrontada com diferentes paradoxos com os quais os docentes se deparam cotidianamente no exercício da docência. Entretanto, diversos autores (REBOLO; BUENO, 2014; JESUS, 2002; DEVELAY, 2004) acreditam existir possibilidades de enfrentamento do mal-estar docente e apresentam que uma das causas desse problema é a solidão do professor frente às problemáticas de seu cotidiano. Sendo uma alternativa para o enfrentamento dar voz ao professor e possibilitar-Ihe um ambiente que o afaste do isolamento no qual tende a resolver seus conflitos.

Nesse sentido, com a finalidade de refletirmos sobre como trabalho docente e a formação de professores do Ensino Médio têm sido discutidos nas produções no campo da educação, delimitamos, nesse artigo, um estudo teórico, realizado a partir do levantamento bibliográfico nas produções da Revista Brasileira de Educação no período de 2000 a 2016 . Propomos como objetivo compreender o que revelam as produções da Revista Brasileira de Educação (RBE), considerando a temática escolhida, a partir de fatores como: número de publicações, autores, universidades, temas abordados, referenciais mais utilizados. Destacamos a relevância, as divergências e recorrências as (ou não) sobre o tema. Tal reflexão surge como um exercício inicial da investigação e sistematização do levantamento bibliográfico, que faz parte de uma pesquisa maior que ainda está em andamento ${ }^{1}$.

\section{METODOLOGIA}

A pesquisa teórica, qualitativa de natureza descritiva e exploratória "[...] poderá servir para determinar impasses e os bloqueios, capazes de entravar um projeto de pesquisa em grande escala. [...] Ela é, a maior parte do tempo, completa em si mesma, e não tem obrigatoriamente necessidade de ser continuada por outros pesquisadores, por meio de outras técnicas". (DESLAURIERS; KÉRISIT, 2010, p. 130).

\footnotetext{
${ }^{1}$ Esse recorte se configura a partir de uma pesquisa teórica maior, que estamos realizando no interior de uma disciplina do programa de PósGraduação em Educação da FCT-UNESP e coordenada por Rinaldi (2017). A disciplina intitula-se "Formação de Professores: dimensão histórica cognitiva, ética, afetiva e de desempenho" e tem como trabalho final, a partir de levantamentos bibliográficos, a construção de um Estado da Arte sobre Formação de professores e Trabalho docente nos diferentes níveis e modalidades de ensino, a saber: Educação infantil, Ensino fundamental, Ensino médio, Ensino superior, Educação profissionalizante e Educação à distância em diferentes bases de dados (ANPAE, ANPED, BDTD, ENDIPE, Revista Brasileira de Educação e Cadernos Cedes).
} 
Em nosso caso, por vincular-se à pesquisa mais ampla, o processo de coleta de dados foi rigorosamente planejado a partir de critérios previamente definidos e orientadores para o levantamento bibliográfico nas diversas bases de dados. Foram utilizados como descritores: trabalho docente, formação docente, formação de professores, desenvolvimento profissional, educação básica, ensino médio e nível médio. Fazendo-se necessário para selecionarmos o trabalho para análise a intersecção das palavras-chave, ou seja: trabalho docente ou formação de professores no ensino médio ou educação básica. Esta forma de seleção evidenciou quão pouco têm sido discutidas as condições de trabalho e a formação docente dos professores que trabalham com o Ensino Médio.

\section{RESULTADOS}

No levantamento da RBE encontramos 459 publicações no período investigado. Selecionamos inicialmente 14 publicações, após a leitura completa, apenas 6 trabalhos atendiam a temática para análise.

Tabela 1. Formação de professores e trabalho docente no ensino médio a partir das publicações da RBE do período de 2000-2016

\begin{tabular}{|c|c|c|}
\hline $\begin{array}{l}\text { ANO/ } \\
\text { VOL. }\end{array}$ & INSTITUIÇÃO DOS AUTORES & TÍTULOS DOS TRABALHOS \\
\hline $\begin{array}{c}\text { Set/Dez } \\
2001\end{array}$ & $\begin{array}{l}\text { Universidade Católica de Goiás, Centro de } \\
\text { Educação; Universidade de São Paulo, Faculdade } \\
\text { de Educação. Região Sudeste/Centro-Oeste }\end{array}$ & 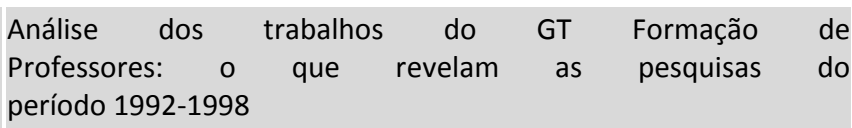 \\
\hline $\begin{array}{l}\text { Jan/Abr. } \\
2007\end{array}$ & $\begin{array}{l}\text { Universidade do Minho, Centro de Estudos da } \\
\text { Criança. Internacional - Europa }\end{array}$ & $\begin{array}{l}\text { Função docente: natureza e construção do conhecimento } \\
\text { profissional }\end{array}$ \\
\hline $\begin{array}{l}\text { Jan./Abr. } \\
2009\end{array}$ & $\begin{array}{l}\text { Universidade Estadual de Campinas, Faculdade } \\
\text { de Educação. Região Sudeste }\end{array}$ & $\begin{array}{l}\text { Formação de professores: aspectos históricos } \\
\text { e teóricos do problema no contexto brasileiro }\end{array}$ \\
\hline $\begin{array}{l}\text { Mai/Ago } \\
2009\end{array}$ & $\begin{array}{l}\text { Universidade Federal de Pelotas, Faculdade de } \\
\text { Educação. Região Sul }\end{array}$ & $\begin{array}{l}\text { "Discutir educação é discutir trabalho docente": o trabalho } \\
\text { docente segundo dirigentes da Confederación de Trabajadores de } \\
\text { la Educación de la República Agentina (CTERA) }\end{array}$ \\
\hline $\begin{array}{l}\text { Jul/Set. } \\
2014\end{array}$ & $\begin{array}{l}\text { Universidade de Brasília, Brasília, DF, Brasil. } \\
\text { Região Centro-Oeste }\end{array}$ & $\begin{array}{l}\text { Política de formação de professores para a educação básica } \\
\text { a questão da igualdade }\end{array}$ \\
\hline $\begin{array}{l}\text { Out.-Dez. } \\
2014\end{array}$ & $\begin{array}{l}\text { Universidade do Minho, Braga, Portugal. } \\
\text { Internacional - Europa }\end{array}$ & $\begin{array}{l}\text { Discursos do profissionalismo docente: paradoxos e alternativas } \\
\text { conceptuais }\end{array}$ \\
\hline
\end{tabular}

Fonte: Dados organizados pelos autores com base no levantamento bibliográfico.

Os dados foram organizados a partir de categorias que objetivaram responder: Quais os problemas de pesquisas encontrados? Quais as temáticas em discussão? Quais os objetivos? Quem são os autores e de quais universidades? De quais regiões? Que representatividades apontam no cenário nacional (ou internacional)? Quais as principais metodologias utilizadas? Quais os principais referenciais teóricos? Em que direções apontam seus resultados? Estas questões nos nortearam em um possível panorama da área, tendo em vista que a base escolhida representa um periódico importante no campo da Educação.

\section{DISCUSSÃO}

Dos 6 trabalhos selecionados, nossa primeira análise refere-se aos períodos de publicações: observamos que não há regularidade, excetuando-se os anos de 2009 e 2014 com duas publicações em cada ano.

As pesquisas publicadas na RBE possuem algumas especificidades, uma delas definimos como "autoridade do autor". Notamos nos trabalhos que não havia definição epistemológica e/ou 
metodológica da pesquisa como qualitativa ou quantitativa, ou se o delineamento é estudo de caso, pesquisa-ação, pesquisa-intervenção, pesquisa documental, etc. Entretanto, a ausência destas informações não comprometeu a qualidade do trabalho. Inferimos que pela representatividade do autor no campo da Educação, tal informação tornou-se supérflua na produção, sendo aproveitado o espaço do texto para problematização e aprofundamento teórico dos assuntos estudados.

Com uma única exceção, os artigos foram publicados por um único autor. Relacionamos esta característica também à "autoridade do autor" que apresenta trabalhos de problematização teórica para contribuir com a ampliação e aprofundamento das discussões de sua linha de investigação.

Em relação às regiões do país em que os pesquisadores se encontram, notamos que os trabalhos foram feitos por pesquisadores vinculados às instituições do centro-oeste, sul e sudeste, com destaque para duas publicações de pesquisadoras da Europa (Portugal).

Quanto à natureza da pesquisa, classificamos os trabalhos em três grandes categorias: Trabalhos Teóricos: que visam discutir com profundidade uma temática, sem apresentar pesquisa empírica, análise de documentos, entrevistas ou questionários - 3 trabalhos se incluíram nesta categoria; Do Tipo Estado da Arte: com os trabalhos que apresentam estudos amplos de levantamentos bibliográficos, com o objetivo de compreenderem a área investigada -1 trabalho se enquadra nesta categoria; Políticas Públicas, Formação e Trabalho Docente: nesta categoria enquadramos os trabalhos que versam sobre as políticas de formação e suas implicações no trabalho docente -2 pesquisas se enquadram nesta categoria. As análises dos trabalhos nos oportunizam compreensão e reflexão sobre o campo investigado. Discorremos abaixo sobre as pesquisas encontradas.

Incluídos na categoria de Trabalhos Teóricos estão os trabalhos de Maria do Céu Roldão (2007), Demerval Saviani (2009) e Maria Assunção Flores (2014).

O artigo de Roldão (2007) apresenta uma reflexão para o campo da profissionalidade docente, a partir de categorias de análise em construção do status profissional em comparação com outras profissões. $O$ trabalho é profundo e extremamente rico. A autora problematiza como o conhecimento profissional docente interfere no desenvolvimento e reconhecimento profissional do professor. Defende como referencial a perspectiva de Montero (2005). Cita como principais referências: Schon (1983), Apple (1997), Shulman (1986, 2004), Goodson (1999), Gimeno Sacristan (1995), Nóvoa (1995) e diversos trabalhos da própria autora. O reconhecimento da profissionalidade da docência é amplamente discutido no texto, evidenciando que a formação do professor enquanto intelectual, profissional é indiscutível para reconhecimento, legitimação e valorização da classe.

O texto de Saviani (2009) apresenta uma discussão histórica da formação de professores considerando os problemas do contexto brasileiro. Articulando a discussão da formação do professor do nível primário e do professor do nível secundário. Em um retorno histórico apresenta com propriedade os períodos que destaca como fundamentais para a compreensão do desenrolar da formação de professores no País. Aponta os dilemas da formação de professores e ensaia uma possibilidade de superação, versa sobre a educação especial e, por fim, conclui seu trabalho. Para contribuir com a fundamentação de sua discussão o autor traz se pauta em referências como: Reis Filho (1995), Vidal (2001), Tanuri (2000), Cavalcante (1994), além de diversos documentos oficiais da educação e textos do próprio autor.

Assunção Flores (2014), por sua vez, expõe uma discussão no âmbito do trabalho docente. Contextualiza o cenário atual a partir das mudanças sociais políticas e culturais que tem interferido significativamente no profissionalismo e identidade docente, de modo a lançar luz a profissionalismo/profissionalização docente. A partir literatura pertinente (HARGREAVES, 2000; 2001; TALBERT; MCLAUGHLIN, 1996; ETZIONI, 1969; GIMENO, 1991; IMBERNÓN, 1994; LARSON, 1977; STENHOUSE, 1975) tem o intuito de apontar tendências, reflexões e analisar os discursos que 
têm marcado as discussões no domínio do profissionalismo docente. A autora conclui que "[...] para além do questionamento das políticas e do modo como estas são implementadas, é essencial analisar a forma como elas têm afetado o trabalho das escolas e dos professores, e fundamentalmente o modo como o seu profissionalismo tem sido (re) definido." (FLORES, 2014, p. 864).

Classificado como Estado da Arte, Iria Brzezinski e Elsa Garrido (2001), apresentam um levantamento bibliográfico sobre os artigos publicados na ANPED no período de 1992-1998 no Grupo de Trabalho (GT) de Formação de Professores. Exibem uma pesquisa densa e detalhada, tendo como material de análise 70 publicações. Como resultados, Brzezinski e Garrido (2001) encontraram grande número de pesquisas que tratavam da formação do professor, seja ela inicial ou continuada, apresentando crítica às formações continuadas pautadas em cursos rápidos, que visam apenas à obtenção de diploma; destacam as parcerias da universidade com o sistema educacional nos processos de formação e de profissionalização docente. As autoras apontam lacunas na direção da ausência de pesquisas que deem voz aos alunos, que compreendam os seus anseios em relação à escola; ausência de pesquisas que tratem da formação de professor formador; bem como de avaliação do impacto dos cursos de formação inicial e a melhoria do ensino e pesquisas que tratem das reais condições de trabalho do professor da rede pública e como tais condições influenciam em sua prática.

Na categoria Políticas Públicas, Formação e Trabalho Docente estão incluídos os trabalhos de Marcia Ondina Vieira Ferreira (2009) e Valdinei Costa Souza (2014).

O trabalho de Ferreira (2009) é peculiar, com uma temática pouco explorada. Apresenta dados de uma pesquisa com sindicalistas em um Sindicato dos Professores da Argentina. Considerando a importância dos agentes dos sindicatos em sua atuação nas discussões de propostas, tentativas de reformas e regulação do trabalho docente, a autora propõe como ideia central a interpretação da situação que a categoria docente vem vivendo a partir da perspectiva do sindicato, sendo a pesquisa realizada com três dirigentes da Confederación de Trabajadores de la Educación de la República Argentina (CTERA). A coleta de dados foi realizada por meio de entrevista. A autora apresenta resultados de reflexões a partir da fala destes representantes, compreendendo a perspectiva destes sobre os docentes como trabalhador em educação e profissional docente. Contextualiza a necessidade de pesquisas desta natureza tendo em vista que os sindicatos representam os professores frente às discussões de ordem política e ideológica, bem como trabalham em prol da formação e do trabalho docente dos professores. Apresenta como apoio teórico os autores: Apple (1987), Birgin (1999), Narodowski (1997), Nóvoa (1991), Gauthier (1998), Tardif (2002), Jiménez Jàen (1991).

O trabalho de Souza (2014) investiga o programa Parfor Presencial com o objetivo de examinar "[...] sua capacidade de reduzir desigualdades regionais e propiciar equidade no acesso de professores da educação básica à formação em serviço" (SOUZA, 2014, p. XX). Propõe análises no domínio das políticas públicas, tendo como referencial Lowi (1994); e Haas (1992) ao abordar o conceito de comunidades epistêmicas. Após uma análise consistente e embasada, conclui que existe uma discrepância entre a necessidade de formação de professores e a real oferta do Parfor, tendo em vista que o programa não privilegia as regiões que possuem maior déficit de professores, destaca também a dificuldade destes professores permanecerem no curso de formação, já que uma das exigências é permanecer em serviço. Tais considerações são provocadoras na compreensão de iniciativas de formação embasada pelas políticas públicas e demonstram que o Programa não tem reduzido as disparidades, tampouco oportunizado igualdade no acesso de professores da educação básica à formação em serviço.

Assim como Rebolo e Bueno (2014), Jesus (2002) e Develay (2004), as pesquisas analisadas partem dos mesmos referenciais que introduzimos a temática neste artigo, autores internacionais que têm lançado luz no campo da formação e do trabalho docente. Chegam aos apontamentos de mesma natureza, que defendem a formação do professor como forma de valorização da profissão 
e reconhecimento da classe docente. Na compreensão da força e importância do trabalho coletivo e ao mesmo tempo individual, partindo do entendimento do próprio contexto do trabalho docente na mobilização de enfrentamentos a realidade posta.

Os resultados evidenciam que considerando a base de dados e o período escolhido - RBE, de 2000 a 2016 - as discussões que envolvem a formação de professores e o trabalho docente com foco no ensino médio têm sido inexistente. Por outro lado, pesquisas de profunda qualidade discutindo a formação e o trabalho docente no âmbito teórico, das políticas públicas, em uma perspectiva de compreensão do campo da formação de professores, foram privilegiadas.

\section{CONCLUSÃO}

Analisando os artigos, a partir do enfoque supramencionado percebemos algumas características: a primeira, relacionada à ausência de discussão da temática no veículo analisado; a segunda, referente à inconstância das publicações ao longo do tempo; a terceira, é que os autores são brasileiros e estrangeiros, sendo eles reconhecidos no campo da educação, em especial no âmbito da formação e trabalho docente, tendo como referenciais de suas pesquisas, maiormente, autores estrangeiros. As pesquisas apresentam-se mais como pesquisas teóricas (ensaios), para reflexão do campo. Destacando-se também as pesquisas que versam sobre as políticas públicas e um estado da arte com o objetivo de mapear as produções da ANPED (1992-1998), algo que acena para uma preocupação com aspectos como a profissionalidade e o profissionalismo do docente. Os artigos também demonstram que o campo da formação de professores e trabalho docente precisa retomar as discussões de enfrentamento enquanto classe, enquanto coletivo, iniciando as discussões "a partir de dentro", comprometidos com a formação intelectual e com a construção e aprimoramento da autonomia docente.

Porém, tais constatações, apesar de extremamente pertinentes, ainda são insuficientes para tratar com profundidade as especificidades da formação e do trabalho docente do professor do nível médio, evidenciando que esta é uma vertente a ser investigada e divulgada em periódicos de qualidade da área da Educação, como é o caso da Revista Brasileira de Educação.

\section{REFERÊNCIAS:}

BRZENZINSKI, I.; GARRIDO, E. Análise dos trabalhos do GT Formação de Professores: o que revelam as pesquisas do período 1992-1998. Revista Brasileira de Educação, n. 18, set-dez, 2001.

DESLAURIERS, J. P.; KÉRISIT, M. O delineamento da pesquisa qualitativa. In: POUPART, J. et al (Org.). A pesquisa qualitativa: enfoques epistemológicos e metodológicos. 2 ed. Petrópolis: Vozes, 2010. p. 127-153.

DEVELAY, M. Por uma nova identidade docente, reconstruída a partir da atividade real da profissão. In: ADÃO, A; MARTINS, E. (Orgs.). Os professores: identidades (re)construídas. Lisboa: Edições Universitárias lusófonas, 2004, p. 55-60.

FERREIRA, M. O. V. "Discutir educação é discutir trabalho docente": o trabalho docente segundo dirigentes da Confederación de Trabajadores de la Educación de la República Argentina (CTERA). Revista Brasileira de Educação, v. 14, n. 41, maio-ago, 2009.

FLORES, M. A. Discursos do profissionalismo docente: paradoxos e alternativas conceptuais. Revista Brasileira de Educação, v. 19, n. 59, out-dez, 2014, https://doi.org/10.1590/S1413$\underline{24782014000900003}$.

JESUS, S. N. Perspectivas para o bem-estar docente: Uma lição de síntese. Porto: ASA, 2002. 63 p. 
LAPO, F. R.; BUENO, B. O. O bem-estar docente: limites e possibilidades para a felicidade no trabalho do professor. Acta Scientiarum education. Maringá, v. 36, n. 2, p. 323-331, july-dec., 2014.

MARIN, A. J. Educação continuada: introdução a uma análise de termos e concepções. Caderno CEDES, n. 36, p. 13-27, 1995.

ROLDÃO, M. do C. Função docente: natureza e construção do conhecimento profissional. Revista Brasileira de Educação, v. 12, n. 34 jan.-abr., 2007, https://doi.org/10.1590/S1413$\underline{24782007000100008}$

SAVIANI, D. Formação de professores: aspectos históricos e teóricos do problema no contexto brasileiro. Revista Brasileira de Educação, v. 14, n. 40, jan.-abr.,2009, https://doi.org/10.1590/S141324782009000100012.

SOUZA, V. C. Política de formação de professores para a educação básica: a questão da igualdade.

Revista Brasileira de Educação, v. 19, n. 58, jul.-set., 2014, https://doi.org/10.1590/S1413$\underline{24782014000800006 .}$. 